\title{
DENDROCHRONOLOGICAL DATING OF THE HISTORIC MCKENZIE HOME, MEIGS COUNTY, TENNESSEE, USA
}

\author{
LAUREN A. STACHOWIAK ${ }^{1 *}$, ELIZABETH A. SCHNEIDER ${ }^{1}$, MAEGEN L. ROCHNER ${ }^{1}$, SAVANNAH A. \\ COLLINS $^{1}$, CHANEY P. SWINEY ${ }^{1}$, HENRI D. GRISSINO-MAYER ${ }^{1}$, and THOMAS G. MCKENZIE ${ }^{2}$ \\ ${ }^{1}$ Laboratory of Tree-Ring Science, Department of Geography, The University of Tennessee, Knoxville, TN, 37996-0925, \\ USA \\ ${ }^{2}$ Meigs County Historical Society, 200 Smith Ave., P.O. Box 43, Decatur, TN, 37322, USA
}

\begin{abstract}
The McKenzie Home is a one-story log structure located in Meigs County, Tennessee. The land tract where the cabin was originally built was purchased by the McKenzie family $c a$. A.D. 1820 to 1828, which makes the suspected construction date for the home sometime after 1820. Our objective was to date oak (Quercus spp.) cross-sections taken from original logs to accurately determine the year when the trees were cut and therefore when the structure was built. We created a master chronology from measurements taken along 12 radii from five oak sections using program COFECHA to first confirm internal crossdating among the measured radii and then using program ARSTAN to create a floating master chronology. Interactive detrending identified two likely disturbances that affected tree growth on all five oaks and these trends were subsequently removed using 32-year splines. The McKenzie floating chronology was then compared with a composite reference chronology created from four oak chronologies located in Tennessee, Kentucky, and Alabama. An interseries correlation coefficient of 0.412 ( $\mathrm{n}=169$ years, $\mathrm{t}=5.84, \mathrm{p}<0.0001$ ) was obtained between the floating chronology and the anchored reference chronology, indicating a single year of tree harvesting in A.D. 1876. Cutting dates for the five samples indicate harvesting began in the early part of the growing season in 1876 and lasted until the end of the growing season or possibly into the dormant season of 1876-1877. The graphical and statistical crossdating evidence and cutting dates that confirm 1876 as the year of construction matches historical property and district records, which state the land was purchased by E.G. McKenzie, Sr. from his brother on 1 February 1876. The log structure has since been renamed the "E.G. McKenzie, Sr. Home."
\end{abstract}

Keywords: tree rings, dendrochronology, construction history, Tennessee, Southeastern US.

\section{INTRODUCTION}

Authenticating the historical significance of structures has become increasingly important to private home owners, private historical agencies, and government agencies involved in preservation. By establishing a construction date of an old homestead and cabin using dendrochronological methods, the date of the structure may secure a successful nomination for placement in the National Register of Historic Places managed by the National Park Service (Parker and King 1998). Many of these structures were built with felled logs,

\footnotetext{
*Corresponding author: 1stachow@utk.edu; Telephone: (262) 391-5630
}

the primary building material during the 19th Century until shaped lumber became widely available from modernization of sawmills. These $\log$ structures can be analyzed through the lens of tree-ring science (Grissino-Mayer 2009). Dendrochronological techniques have become a welldeveloped and applicable method for the accurate dating of the year of construction for historic log structures throughout the Southeastern United States (Stahle 1979; Stahle and Wolfman 1985; Grissino-Mayer and van de Gevel 2007; Mann et al. 2009; Henderson et al. 2009; Slayton et al. 2009; Harley et al. 2011; Grissino-Mayer et al. 2013).

The McKenzie Home $\left(35.409725^{\circ} \mathrm{N}, 84.866441^{\circ} \mathrm{W}\right)$ was originally located in Meigs County in southeastern Tennessee (Figure 1) on a tract of land 


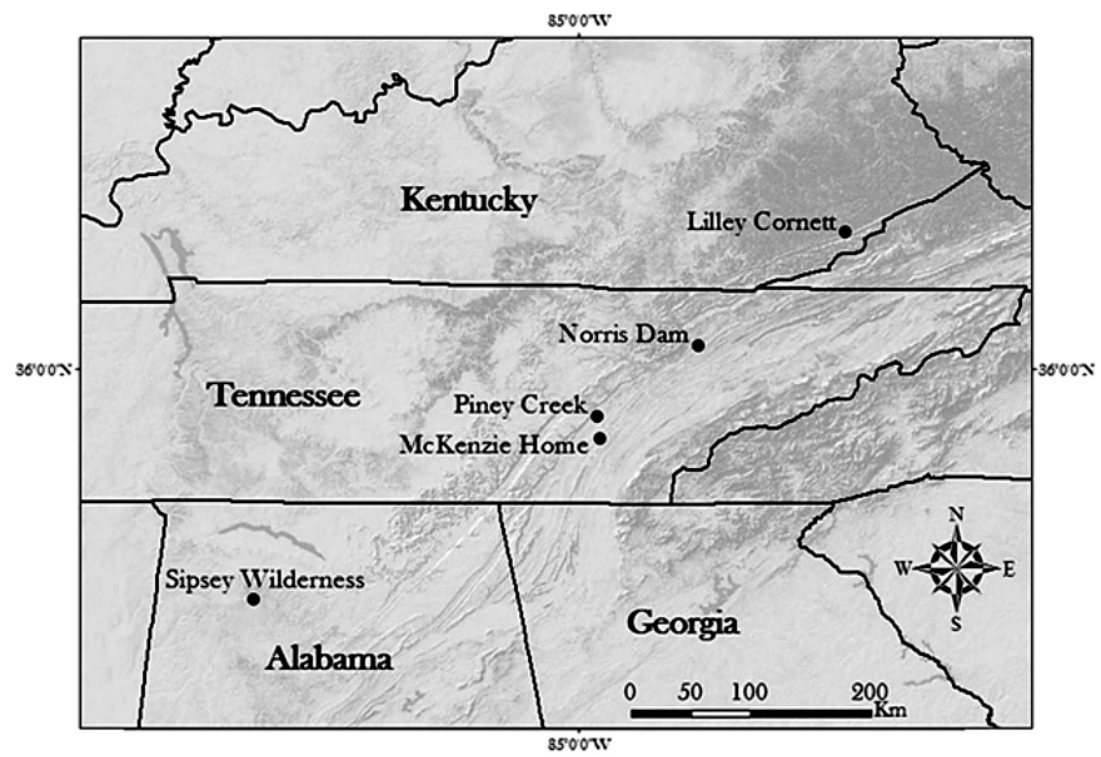

Figure 1. Locations of the McKenzie Home and the four reference chronologies used to form the composite chronology.

known as the Hiwassee Purchase that had been subdivided into 160 -acre ( 65 hectare) parcels by the Hiwassee District Survey for purchase by settlers beginning $c a$. A.D. 1820. One of those original settlers on the home's location was either Benjamin Franklin McKenzie, Sr. or Benjamin Franklin McKenzie, Jr. who established the land as a family farm, leading to the speculation that the log home was constructed soon after. Earliest available deed references mention only that the property on which the structure was built was "a portion of the B.F. McKenzie tract of land" but we do not know which B.F. McKenzie owned this particular parcel (Broyles 1989). The original log home was disassembled about 10 years ago, transported to a nearby location about $8 \mathrm{~km}$ away $\left(35.479394^{\circ} \mathrm{N}\right.$, $84.834885^{\circ} \mathrm{W}$ ), and systematically reassembled using $\log$ numbers to ensure each log was placed back in its original position (Figure 2). During reconstruction, the original brick or stone chimneys on each end were left open, thus exposing the ends of several logs from which samples could be obtained for dendrochronological analysis.

The samples analyzed in our study came from $\log$ ends from the chimney that once stood to the left of the original cabin (Figure 2). We acquired five cross-sections from the ends of these exposed logs and analyzed them with dendrochronological dating methods. The logs displayed what appeared to be a continuous surface on the upper and lower unhewn portions of the logs, making it possible to obtain the year(s) the trees were harvested to make the log structure. When initially building pioneer $\log$ structures in the Southeastern US, settlers

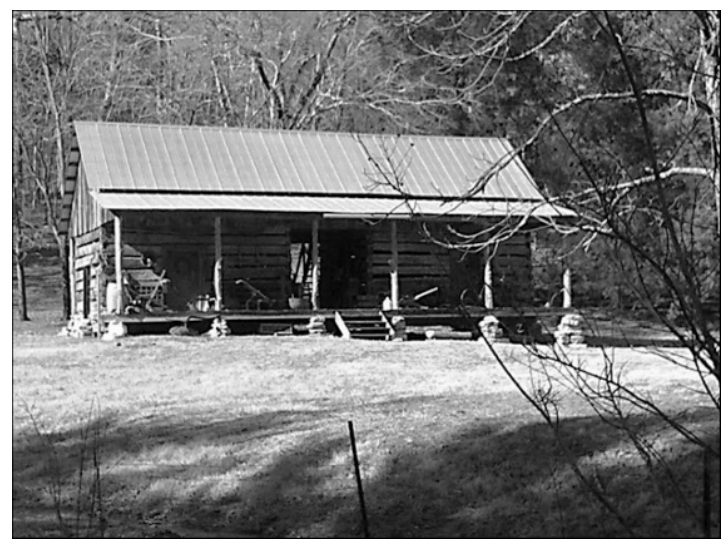

Figure 2. The McKenzie Home reassembled at its new location in Meigs County, Tennessee. The house is a double-pen construction separated by a central dogtrot ("breezeway"). The metal roofing is more recent. The original brick chimneys at both ends of the structure are no longer present. The five samples for our study came from the ends of exposed logs where the chimney to the left once stood (photo courtesy of the Thomas McKenzie family). 
often would leave the bark intact on these two portions of the log, which would then be covered with mud daubing (or "chinking"), thus preserving the outermost ring. The objective of this project was to precisely date the tree rings from sections cut from five oak logs, focusing particularly on the outermost ring to determine the exact year(s) the trees were cut and the house likely built. Early settlers integrated the harvested trees into the structure immediately after felling because seasoning was not practiced as seasoned wood was more difficult to hew and shape (Grissino-Mayer 2009).

\section{METHODS}

\section{Species Identification}

Initial processing began with species identification because log structures can be built with various hardwood and softwood species. The samples we analyzed were classified in the white oak group and could be either white oak (Quercus alba L.), post oak (Q. stellata Wangenh.), or chestnut oak (Q. montana Willd.) based on known range distributions. Because of the durable nature of the wood, oak trees were commonly used for building construction in the Southeastern United States during settlement periods (Grissino-Mayer 2009; Harley et al. 2011).

Each section was mounted and then sanded using progressively finer sandpaper beginning with ANSI 100-grit $(125-149 \mu \mathrm{m})$ and ending with ANSI 400-grit (20.6-23.6 $\mu \mathrm{m})$ (Orvis and Grissino-Mayer 2002) (Figure 3). Hand-finishing with ANSI 1200grit $(4.5-6.5 \mu \mathrm{m})$ was used to further polish the sections for visual acuity. We used a binocular stereozoom microscope with standard $10 \times$ magnification to initially mark all rings with standard dot notation (Stokes and Smiley 1996; Speer 2010) beginning with the first innermost complete ring labeled as ring "1". All rings were then measured to 0.001-mm accuracy using a Velmex measuring stage and digital display coupled with MEASURE $\mathrm{J} 2 \mathrm{X}$ software.

\section{Internal Crossdating}

We used the computer program COFECHA to perform segmented time-series correlation analyses (Holmes 1983; Grissino-Mayer 2001) on the 12

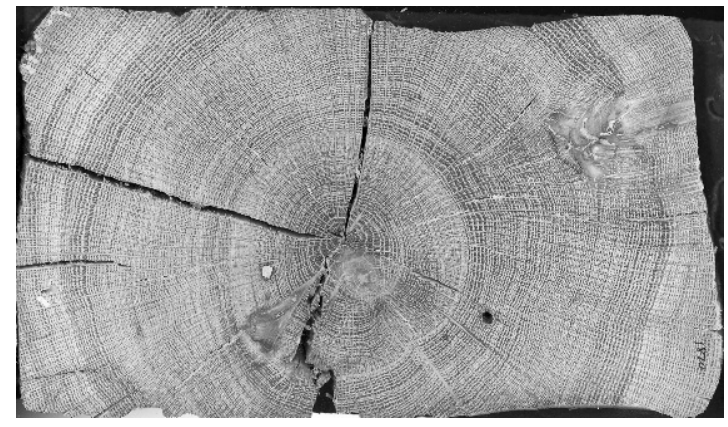

Figure 3. Scanned image of sample MCK002 with outer date of 1876 (lower-right). Note the extended period of growth suppression during the first $c a$. 60 years of growth, likely caused by continued growth while in a sub-canopy position. This suppression contributed to the low correlations (Table 1) in the early segments for this sample.

undated series to place each series in proper temporal alignment with all other series. Log transformations and spline-fitting, along with autoregressive modeling, are applied in the COFECHA software to remove low-frequency trends and highlight year-to-year variation (Grissino-Mayer 2001). We analyzed 40-year segments lagged by 20 years to ensure that most if not all segments crossdated with the same calendar segment from the other series. In the Southeastern US, we use a minimum interseries correlation coefficient of 0.40 (International Tree-Ring Data Bank (ITRDB) 2013a) to indicate that a series has been crossdated correctly relative to other series.

\section{External Crossdating}

Absolute dating was accomplished by crossdating the undated tree-ring series against a composite reference chronology created from four white oak tree-ring chronologies from Tennessee, Kentucky, and Alabama extracted from the ITRDB (Grissino-Mayer and Fritts 1997) (Figure 1). Chronologies KY003 and AL001 were created by Dr. Edward R. Cook of the Lamont-Doherty Earth Observatory at Columbia University, whereas chronologies TN005 and TN008 were created by Dr. Daniel N. Duvick of Oak Ridge National Laboratory in Tennessee:

1. KY003, Lilley Cornett Tract, $37.0289^{\circ} \mathrm{N}$, $83.0017^{\circ} \mathrm{W}, 1660-1982$; 


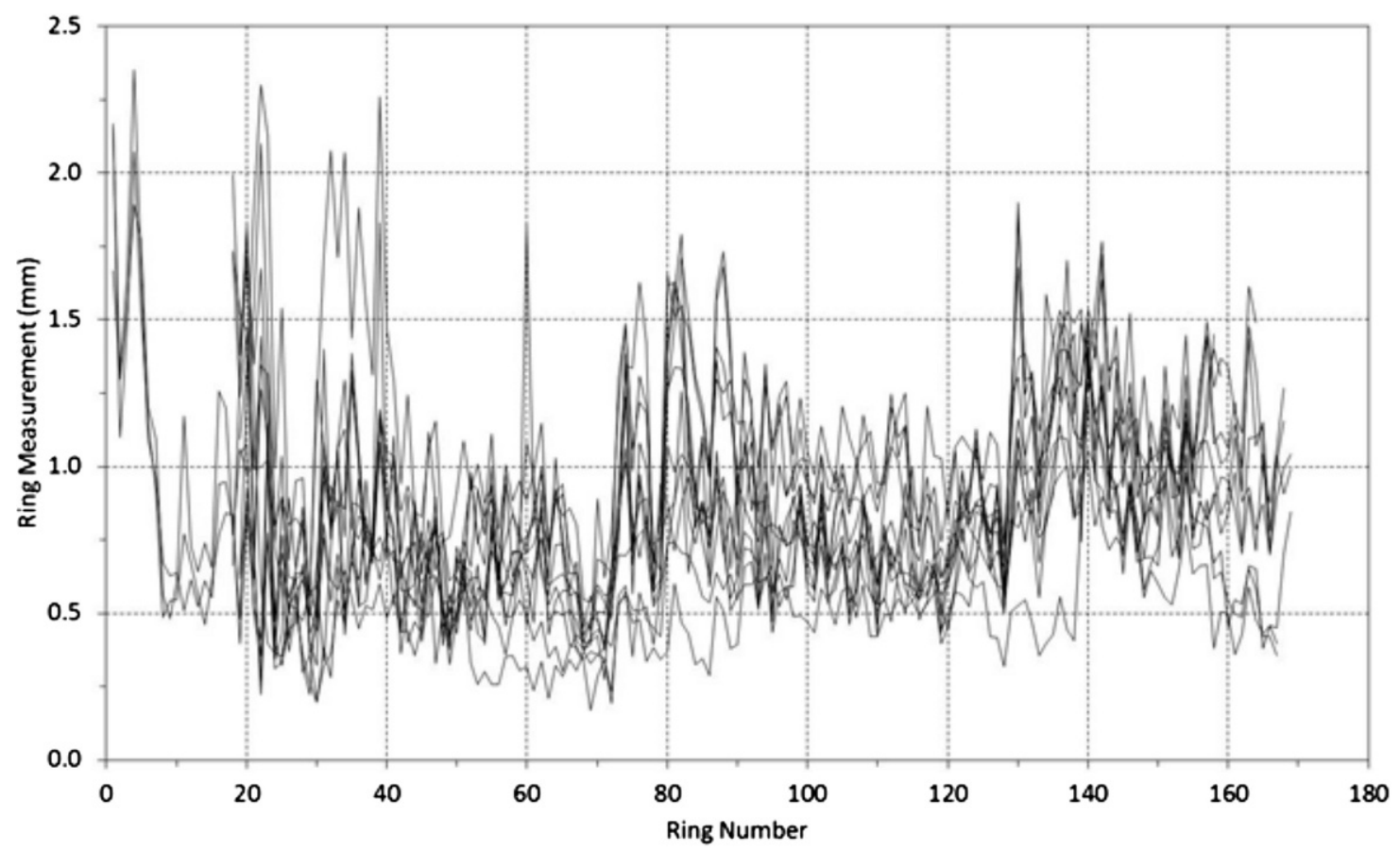

Figure 4. "Spaghetti" plot overlaying all 12 measurement series, showing two major release events from possible disturbances, the first occurring $c a$. ring 73 and the second occurring $c a$. ring 128, such that negative exponential/linear detrending proved insufficient. We instead chose a 32-year spline for detrending. Once absolutely dated, these disturbances occurred $c a$. A.D. 1777 and 1832 . The first release can be clearly seen in sample MCK002 (Figure 3).

2. TN005, Piney Creek Pocket Wilderness, $35.6484^{\circ} \mathrm{N}, 84.8584^{\circ} \mathrm{W}, 1651-1982$;

3. TN008, Norris Dam State Park, $36.1734^{\circ} \mathrm{N}, 84.1003^{\circ} \mathrm{W}, 1633-1980$;

4. AL001, Sipsey Wilderness, $34.2799^{\circ} \mathrm{N}$, 87.4292 ${ }^{\circ} \mathrm{W}, 1679-1985$.

The reference chronologies were selected to match Quercus spp. relative historical depth back in time to at least $c a$. A.D. 1700 that proximal locations in the Tennessee Valley that stretches from northern Alabama through east Tennessee and into central Virginia (Amick 1934). Furthermore, these four data sets have an average interseries correlation of 0.53 indicating a strong response to regional climate necessary to date treering sequences from historic structures. We used COFECHA to suggest temporal placements for each individual series and we considered the series as being crossdated when correlation coefficients for all segments were statistically significant (generally $\mathrm{p}<0.0001$ ).
The individual-series dating adjustments were also verified by testing the correlation between a standard chronology created from the undated series and the composite reference chronology. We standardized our measurement series using the computer program ARSTAN (Cook et al. 2007) (Windows version 4.1d), which provides interactive detrending and enhanced graphics capabilities that assist in detecting unusual trends in tree-ring data and selecting appropriate models for detrending the raw measurement data. Initial detrending was performed with a negative exponential curve or straight line of any slope, but we discovered two likely incidents of major growth releases, possibly caused by disturbance events (Figure 4). Therefore, a 32-year spline was chosen as the final detrending option for each series because it was better at capturing and modeling the trends and/or disturbances that were clearly visible in the measurement data.

Once crossdated, we assigned calendar years to all tree rings on each measurement series from the five samples using program EDRM (Edit Ring 
Table 1. Correlation coefficients that demonstrate successful internal crossdating among the undated cores collected from the McKenzie Home.

\begin{tabular}{|c|c|c|c|c|c|c|c|c|c|c|}
\hline \multirow[b]{2}{*}{ Series } & \multirow[b]{2}{*}{ First Ring } & \multirow[b]{2}{*}{ Last Ring } & \multicolumn{8}{|c|}{ Segment Tested } \\
\hline & & & $0-39$ & $20-59$ & $40-79$ & $60-99$ & $80-119$ & $100-139$ & $120-159$ & $140-179$ \\
\hline & & & \multicolumn{8}{|c|}{ Correlation Coefficient } \\
\hline MCK001A & 1 & 159 & 0.71 & 0.68 & 0.71 & 0.66 & 0.56 & 0.74 & 0.77 & \\
\hline MCK001B & 1 & 164 & 0.72 & 0.58 & 0.65 & 0.77 & 0.59 & 0.64 & 0.65 & 0.69 \\
\hline MCK001C & 1 & 158 & 0.71 & 0.69 & 0.73 & 0.73 & 0.55 & 0.64 & 0.71 & \\
\hline МСK002B & 19 & 149 & $0.33^{*}$ & $0.34 *$ & $0.31 *$ & 0.65 & 0.71 & 0.63 & 0.56 & \\
\hline MCK002C & 19 & 168 & 0.41 & 0.43 & 0.47 & 0.47 & 0.54 & 0.67 & 0.64 & 0.73 \\
\hline MCK003A & 19 & 168 & 0.49 & 0.48 & 0.54 & 0.75 & 0.66 & 0.67 & 0.74 & 0.74 \\
\hline МCK003B & 19 & 169 & 0.49 & 0.51 & 0.48 & 0.56 & $0.36^{*}$ & 0.56 & 0.79 & 0.69 \\
\hline MCK003C & 19 & 169 & 0.39 & 0.40 & 0.50 & 0.65 & 0.50 & 0.62 & 0.78 & 0.61 \\
\hline MCK004A & 18 & 168 & 0.51 & 0.50 & 0.69 & 0.72 & 0.72 & 0.83 & 0.75 & 0.61 \\
\hline MCK004B & 18 & 169 & $0.22 *$ & $0.23 *$ & $0.29 *$ & 0.70 & 0.59 & 0.63 & 0.59 & 0.53 \\
\hline MCK004C & 18 & 167 & 0.56 & 0.56 & 0.65 & 0.66 & 0.61 & 0.63 & 0.68 & 0.58 \\
\hline MCK005A & 18 & 166 & 0.49 & 0.53 & 0.49 & 0.49 & 0.54 & 0.52 & 0.45 & 0.42 \\
\hline \multicolumn{3}{|c|}{ Average correlation } & 0.50 & 0.49 & 0.54 & 0.65 & 0.58 & 0.65 & 0.68 & 0.62 \\
\hline
\end{tabular}

* Indicates a 40-year segment flagged by COFECHA because of low correlations. Re-inspection found these segments to be dated correctly.

Measurement) (Holmes 1992). Crossdating was verified graphically by inspection of line graphs that compared the crossdated residual chronology for the McKenzie Home against the composite residual chronology created from the reference chronologies.

\section{Establishing Cutting Dates}

Once all tree rings on the McKenzie Home were crossdated and assigned calendar years, we carefully examined the outermost dated ring on each cross-section under high magnification. Standard symbols were assigned to help evaluate the possible year of cutting (after Bannister et al. 1966 and Nash 1999):

B: Bark was present, indicating the outermost ring is intact (cutting date),

$r$ : The outermost ring is intact, around a smooth curvature (considered a cutting date),

v: The date is within a few years of the cutting date, based on the amount of sapwood, present (a near cutting date),

vv: A cutting date is not possible because we could not determine how far we are from the outermost ring.

\section{RESULTS}

We measured 14 transects on the five crosssections extracted from the house, but only 12 measurement series were suitable for crossdating (the other two series encountered erratic growth, being taken too close to branches and other growth anomalies). These 12 series had an average interseries correlation of 0.57 , which is exceptionally high for measurement series from southeastern trees. Only seven of the 9340 -year segments tested $(7.5 \%)$ in these 12 series were flagged by COFECHA as being problematic (Table 1), and these were re-inspected. Six of the flagged segments occurred because of very tight and rather complacent growth near the innermost 60-70 rings on two sections (Table 1) (Figure 3) and were not caused by crossdating errors. The average mean sensitivity of these 12 series was 0.22 , identical to the average of 145 data sets for the white oak group (white, post, and chestnut oak) held in the ITRDB (ITRDB 2013b). In the Southeastern US, we typically require a minimum mean sensitivity value of 0.20 to indicate the necessary climate sensitivity required for crossdating.

When the floating McKenzie Home chronology was tested against the composite reference chronology for the region, COFECHA found that 


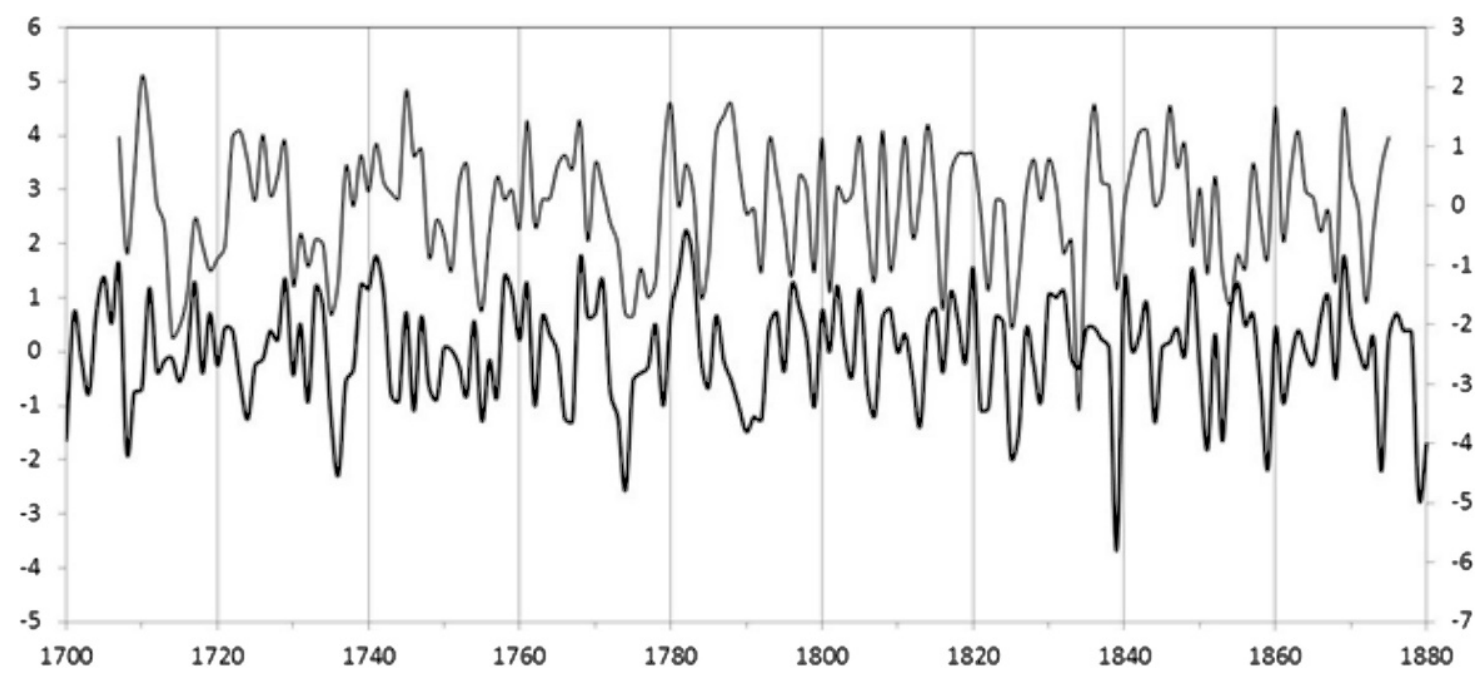

Figure 5. Graphical correspondence between the McKenzie Home chronology (top) and the composite chronology (bottom) created from the four regional oak reference chronologies $(r=0.412, n=169$ years, $t=5.84, p<0.0001)$. Both chronologies represent the master dating chronologies produced by COFECHA and are therefore residual chronologies with mean $=0.0$.

six of the seven 40-year segments tested required a systematic dating adjustment of " +1706 " with an average correlation for these six segments of 0.42 . No other systematic dating adjustment was found by COFECHA. The correlation coefficient between the chronology from the McKenzie Home and the composite reference chronology was 0.41 $(\mathrm{n}=169$ years, $\mathrm{t}=5.84, \mathrm{p}<0.0001)$. Graphical comparison of the two chronologies showed a strong and convincing match, indicating successful crossdating (Figure 5). These results confirmed that the first year of the floating McKenzie Home chronology was anchored in A.D. 1707 and the last measured tree ring was therefore formed in 1875. Three logs (MCK002, MCK003, and MCK005) were harvested in 1876, while another $\log$ (MCK004) was likely harvested in early 1876 before the growing season began (Table 2). The fifth $\log$, MCK001, did not have a continuous outer ring surface and therefore had an earlier outer ring of 1871 .

\section{DISCUSSION}

The five trees used to build the McKenzie Home were all likely cut in A.D. 1876 and the log home constructed later in the growing season of that year or soon after. Temperate forest deciduous tree species in the Southeastern US typically experience leaf-out by mid-March to early April (days 75 to 95) during a year in which winter and spring temperatures are considered near average (Gu et al. 2008), suggesting that bud break begins slightly earlier. By comparing the estimated timing of bud break and the number of earlywood vessels present on the outer ring of the sample, we can approximate the month in which the tree was cut.

Two samples, MCK002 and MCK005, displayed outermost rings formed in A.D. 1876 with just the earlywood vessels present, indicating these trees were harvested soon after bud break. To evaluate climate conditions in the year 1876 with which to help determine more precisely when during the growing season these trees were likely harvested, we used reconstructed PDSI (Palmer Drought Severity Index) based on the gridded network of tree-ring sites throughout the United States (Cook and Krusic 2004). Inspection of reconstructed PDSI in 1876 for grid point 229 (southeastern Tennessee) showed a value of 0.82 (incipient wet conditions) after a year in which incipient drought occurred (A.D. 1875, PDSI = $-0.344)$. These indicate trees would have broken dormancy in spring neither earlier nor later than usual, suggesting the trees used to create logs MCK002 and MCK005 were perhaps cut in March or April 1876. Sample MCK003 contained bark and what likely was a complete or near-complete 
Table 2. Inner ring and outer ring dates and types from logs sampled at the McKenzie Home.

\begin{tabular}{lccl}
\hline \multicolumn{1}{c}{ Series } & Inner Ring & Outer Ring $*$ & \multicolumn{1}{c}{ Comments } \\
\hline MCK001A & 1707 & $1866 \mathrm{vv}$ & Non-cutting date, sapwood present \\
MCK001B & 1707 & $1871 \mathrm{vv}$ & Non-cutting date, sapwood present \\
MCK001C & 1707 & $1865 \mathrm{vv}$ & Non-cutting date, sapwood present \\
MCK002B & 1725 & $1876 \mathrm{r}$ & EW vessels present only, tree cut in spring 1876 \\
MCK002C & 1725 & $1856 \mathrm{vv}$ & Non-cutting date, no sapwood present \\
MCK003A & 1725 & $1875 \mathrm{v}$ & Ring appears complete, but smooth surface absent \\
MCK003B & 1725 & $1876 \mathrm{~B}$ & LW present, tree cut in late 1876/dormant season 1876-1877 \\
MCK003C & 1725 & $1876 \mathrm{~B}$ & LW present, tree cut in late 1876/dormant season 1876-1877 \\
MCK004A & 1724 & $1874 \mathrm{v}$ & Ring appears complete, but smooth surface absent \\
MCK004B & 1724 & $1875 \mathrm{r}$ & LW present, tree cut in late 1875/dormant season 1875-1876 \\
MCK004C & 1724 & $1874 \mathrm{v}$ & Ring appears complete, but smooth surface absent \\
MCK005A & 1724 & $1876 \mathrm{r}$ & EW vessels present only, tree cut in spring 1876 \\
\hline
\end{tabular}

* See text for outer ring type definitions.

ring for 1876, suggesting this tree was harvested late in the growing season of 1876 or perhaps during the dormant season of 1876-1877. Sample MCK004 had an outermost ring of 1875, which appeared to be complete or near-complete, indicating this tree was cut anywhere from the late portion of the growing season for 1875 to the dormant season of 1875-1876. Given the cutting dates of the other logs, this tree was likely harvested in early 1876 during the dormant season, just before bud break.

Four trees had innermost measured rings formed within only a two-year period, A.D. 17241725 , prompting us to question whether these four logs were actually cut from one very large tree, an unlikely scenario given this would have required a tree at least $24 \mathrm{~m}$ in height, but one that needed to be tested. We entered the measurements from these four trees into COFECHA as undated series and found very high correlations among all four trees (e.g. MCK001 versus MCK003, $\mathrm{r}=0.51, \mathrm{n}=141, \mathrm{t}$ $=6.99, \mathrm{p}<0.0001 ;$ MCK003 versus $\mathrm{MCK} 005, \mathrm{r}=$ $0.45, \mathrm{n}=148, \mathrm{t}=6.09, \mathrm{p}<0.0001)$, but none that approached the within-tree correlations we observed (e.g. MCK001A versus MCK001C, $\mathrm{r}=0.70$, $\mathrm{n}=158, \mathrm{t}=12.24)$. These results suggest that the four trees germinated within two years of each other, an uncommon situation for trees used to construct log structures in the Southeastern US Because disturbance events were observed within the measurement series for all five trees, we conclude that a possible disturbance event created optimal environmental conditions for near-simultaneous establishment. Alternatively, a mast event (Speer 2001) that produced a copious acorn crop may have occurred.

The home was originally thought to have been constructed not long after A.D. 1820 based on 1821-1829 tax lists that document the original ownership by Benjamin Franklin McKenzie (Sr. or Jr.) of the 160 acre tract in the Hiwassee Purchase (Broyles 1989). Once we determined the logs were cut in 1876, however, we re-visited the historical documentation and were able to plot the original location of the 160-acre tract by applying coordinates found in the deed and in the Hiwassee District Survey. We discovered that this tract of land was purchased by E. G. McKenzie, Sr. (b. 1836, d. 1910) on 1 February 1876 from his brother, J. M. McKenzie. E. G McKenzie, Sr. and J. M. McKenzie were the sons of B. F. McKenzie, Jr., B. F. McKenzie, Jr., or his father, B. F. McKenzie, Sr. originally purchased/settled the tract between 1820 and 1829. Our results substantiate that E. G. McKenzie, Sr. built the home soon after he purchased the tract of land from his brother, cutting oak trees almost immediately based on the outer ring calendar dates we obtained in our study and the amount of intra-annual wood that had formed. E. G. McKenzie, Sr. had married Penelope Amanda Runyan on 16 January 1858 and then served as a Second Lieutenant in the $5^{\text {th }}$ Tennessee Cavalry of the Confederacy during the Civil War. Curiously, the log home was reassembled on the 
farm of Mr. Ken and Ms. Paulette Jones. Ms. Jones is currently the President of the Meigs County Historical Society and also is a relative of Penelope Runyan McKenzie. This project therefore provided not only accurate and precise dating of a historic structure using dendrochronology, but also provided a more concrete family history and genealogy for the McKenzie Family that was instrumental for understanding the history of Meigs County, Tennessee, during the 19th Century. The home is now appropriately called the "E. G. McKenzie, Sr. Home."

\section{ACKNOWLEDGMENTS}

We thank Ms. Paulette Jones and the Meigs County Historical Society for providing the platform on which to conduct this research, and for helping preserve the E. G. McKenzie, Sr. Home before it deteriorated beyond salvage. We would also like to thank the two anonymous reviewers for their valuable edits and suggestions to the manuscript.

\section{REFERENCES CITED}

Amick, H. C., 1934. The Great Valley of East Tennessee. Economic Geography 10:35-52.

Bannister, B., E. A. Gell, and J. W. Hannah, 1966. Tree-Ring Dates from Arizona N-Q: Verde-Show Low-St. Johns Area. Laboratory of Tree-Ring Research, The University of Arizona, Tucson.

Broyles, B. J., 1989. Rhea County, Tennessee Tax Lists 1819 through 1829. Rhea County Historical and Genealogical Society, Dayton, Tennessee, (Note: The home resides in Meigs County which was formed in 1836 from a part of Rhea County.)

Cook, E. R., and P. J. Krusic, 2007. Program ARSTAN Version 41d. http://www.ldeo.columbia.edu/tree-ring-laboratory. Last accessed 15 August 2013.

- 2004. The North American Drought Atlas. Columbia University Lamont-Doherty Earth Observatory and the National Science Foundation. http://iridl.ldeo.columbia.edu/ SOURCES/.LDEO/.TRL/.NADA2004/.pdsi-atlas.html. Accessed 20 April 2013.

Grissino-Mayer, H. D., 2001. Evaluating crossdating accuracy: A manual and tutorial for the computer program COFECHA. Tree-Ring Research 57:205-221.

2009. An introduction to dendroarcheology in the Southeastern United States. Tree-Ring Research 65:4-10.

Grissino-Mayer, H. D., and H. C. Fritts, 1997. The International Tree-Ring Data Bank: An enhanced global database serving the global scientific community. Holocene 7:235-238.
Grissino-Mayer, H. D., and S. L. van de Gevel, 2007. Tell-tale trees: historical dendroarcheology of log structures at Rocky Mount, Piney Flats, Tennessee. Historical Archaeology 41: 32- 49.

Grissino-Mayer, H. D., J. T. Maxwell, G. L. Harley, N. A. Garland, D. H. Holt, C. Absher, B. J. Beale, M. S. Boehm, K. A. de Graauw, A. M. Rautio, and A. W. Dye, 2013. Dendrochronology reveals the construction history of an early 19th century farm settlement, southwestern Virginia, U.S.A. Journal of Archaeological Science 40:481-489.

Gu, L., P. J. Hanson, W. M. Post, D. P. Kaiser, B. Yang, R. Nemani, S. G. Pallardy, and T. Meyers, 2008. The 2007 eastern US spring freeze: Increased cold damage in a warming world. BioScience 58:253-262.

Harley, G. L., H. D. Grissino-Mayer, L. B. LaForest, and P. McCauley, 2011. Dendrochronological dating of the LundSpathelf House, Ann Arbor, Michigan, U.S.A. Tree-Ring Research 67:117-121.

Henderson, J. P., H. D. Grissino-Mayer, S. L. van de Gevel, and J. L. Hart, 2009. The historical dendroarcheology of the Hoskins House, Tannenbaum Historic Park, Greensboro, North Carolina, U.S.A. Tree-Ring Research 65:37-45.

Holmes, R. L., 1983. Computer-assisted quality control in treering dating and measurement. Tree-Ring Bulletin 43:69-78.

- 1992. User's Manual for Program EDRM. Laboratory of Tree-Ring Research. The University of Arizona, Tucson.

International Tree-Ring Data Bank (ITRDB), 2013a. User Guide to COFECHA Output Files. http://www.ncdc.noaa. gov/paleo/treering/cofecha/userguide.html. Last accessed 15 August 2013.

International Tree-Ring Data Bank (ITRDB), 2013b. Median COFECHA Chronology Statistics by Species. http://www. ncdc.noaa.gov/paleo/treering/cofecha/speciesdata.html. Last accessed 8 May 2013.

Mann, D. F., H. D. Grissino-Mayer, C. H. Faulkner, and J. B. Rehder, 2009. From blockhouse to hog house: the historical dendroarcheology of the Swaggerty Blockhouse, Cocke County, Tennesse, U.S.A. Tree-Ring Research 65:57-67.

Nash, S. E., 1999. Time, Trees, and Prehistory: Tree-Ring Dating and the Development of North American Archaeology, 1914-1950. University of Utah Press, Salt Lake City.

Orvis, K. H., and H. D. Grissino-Mayer, 2002. Standardizing the reporting of abrasive papers used to surface tree-ring samples. Tree-Ring Research 58:47-50.

Parker, P. L., and T. F. King, 1998. Guidelines for Evaluating and Documenting Traditional Cultural Properties. US Department of the Interior, National Park Service, National Register, History and Education, National Register of Historic Places.

Slayton, J. D., M. R. Stevens, H. D. Grissino-Mayer, and C. H. Faulkner, 2009. The historical dendroarcheology of two log structures at the Marble Springs Historic Site, Knox County, Tennessee, U.S.A. Tree-Ring Research 65:23-39.

Speer, J. H., 2001. Oak Mast History from Dendrochronology: A New Technique Demonstrated in the Southern Appalachian Region. Ph.D. dissertation, The University of Tennessee-Knoxville.

$$
\text { 2010. Fundamentals of Tree-Ring Research. The }
$$
University of Arizona Press, Tucson. 
Stahle, D. W., 1979. Tree-ring dating of historic buildings in Arkansas. Tree-Ring Bulletin 39:1-28.

Stahle, D. W., and D. Wolfman, 1985. The potential for archaeological tree-ring dating in eastern North America. Advances in Archaeological Method and Theory 8:279-302.
Stokes, M. A., and T. L. Smiley, 1968. An Introduction to TreeRing Dating. The University of Arizona Press, Tucson.

Received 10 June 2013; accepted 1 November 2013. 